\title{
Determination on Outdoor Stocking Density of Free-range Broiler in Different Ecosystems Based on Nitrogen Cycling
}

\author{
Chaowu Yang, ${ }^{1, *}$, Mohan Qiu $^{2}$, Longhuan Du ${ }^{3}$, Zengrong Zhang ${ }^{1,2}$, Xiaoyan Song ${ }^{1,2}$, Xia Xiong ${ }^{2}$,Chenming Hu ${ }^{1,2}$, Li Yang $^{2}$, \\ Chunlin $\mathrm{Yu}^{2, *}$ \\ ${ }^{1}$ Sichuan Animal Science Academy, 610066, Chengdu, Sichuan, China \\ ${ }^{2}$ Animal Breeding and Genetics Key Laboratory of Sichuan Province, 610066, Chengdu, Sichuan, China \\ ${ }^{3}$ Sichuan University , 610000, Chengdu, Sichuan, China
}

\begin{abstract}
The free-range broiler production is an effective combination of ecological and economic benefits. However, excessive stocking will inevitably lead to a variety of negative effects, such as the destruction of vegetation, the hardening and even acidification of soil. It is very important to determine the reasonable stocking density for free-range broiler. In this paper, the outdoor feeding density of free-range broiler in different stocking ecosystems based on the nitrogen cycling was proposed combination of theoretical derivation and investigation and research, and proved the correctness of the research idea and density parameters through empirical research, which provided the key technical parameters for scientific guidance of free range chicken production.
\end{abstract}

\section{Introduction}

The free-range broiler production has exceeded 30 percent of the total broiler production in China; it is an effective combination of ecological and economic benefits. Based on the utilization of natural resources such as woodland, orchard, grassland and barren hills, chickens ingested range components in the form of vegetation, insects, stones and grit, which offered various of nutrition and were proved to be acceptable for them[1-2]. However, excessive stocking will inevitably lead to a variety of negative effects, such as the destruction of vegetation, the hardening and even acidification of soil. Problems with surface and ground water pollution can result from improper rates of chicken manure application to agricultural land [3]. Kratz et al. [4] analyzed the changes in soil nitrogen and phosphorus under different broiler production systems. The results showed that fecal nitrogen and phosphorus input leaded to accumulation of soil mineral nitrogen and phosphorus, and consequently caused a fact that the soil nitrogen and phosphorus exceeded the upper limit defined in Germany for grassland or optimum plant yield as mentioned by Kratz et al[4]. Their study also indicated an enhanced risk of phosphorus loss from the soil via runoff or leaching, as well as an increased environmental risk of ammonia volatilization and nitrate leaching. As a whole, the minerals and nutritional nomponents of soil are affected by interactions between vegetation type, location, and soil depth [5]. In order to ensure the healthy growth of free-range Broiler and the stability of the ecosystem, it is very important to determine the reasonable stocking density. In this paper, the stocking density of free-range broiler production in different ecosystems was proposed based on the study of nitrogen cycle.

\section{Materials and methods}

\subsection{Determination of nitrogen content}

Three hundred broilers (Dahen 699 broiler, bred by Sichuan Animal Science Academy, China )were caged at 70 days of age, and the birds were fed a diet containing $20 \%$ protein. All the excretions were collected during the experiment period and the nitrogen content in the excretion of each broiler was measured.

\subsection{Determination of nitrogen carrying capacity}

The nitrogen carrying capacity of different stocking sites was determined according to the characteristics of vegetation based on the methods of literature review and investigation.

\subsection{Determination of outdoor stocking density}

We determined the outdoor stocking density of free-range broiler in different ecosystems according to the following steps, (1) Annual nitrogen excretion of broilers; (2) The nitrogen carrying capacity of different stocking sites; (3) The proportion of nitrogen content in artificial fertilization; (4) Annual feeding batches.

* Corresponding author: cwyang@foxmail.com; yuchunlin1984@sina.com 


\subsection{Empirical research}

The outdoor stocking density of free-range broiler in different ecosystems based on nitrogen cycling was used for empirical research.

The experimental site is located in Daoming Town, Chengdu City, Sichuan Province of China $\left(103^{\circ} 07^{\prime} \mathrm{E} \sim\right.$ $103^{\circ} 49^{\prime} \mathrm{E}, 30^{\circ} 30^{\prime} \mathrm{N} \sim 30^{\circ} 53^{\prime} \mathrm{N}$ ), with hills and plains accounting for about $50 \%$ of each other. Daoming Town has a subtropical monsoon climate with four distinct seasons, mild climate and an annual average temperature of $16^{\circ} \mathrm{C}$, a minimum temperature of $5.9^{\circ} \mathrm{C}$ in winter, a maximum temperature of $35^{\circ} \mathrm{C}$ in summer and an annual rainfall of about 1,000 millimeters. Daoming Town is located in a humid subtropical region with complex topography, diverse natural ecological environment and abundant biological resources. The forest coverage rate of the experimental site is $39.10 \%$. The environmental and climate of the experimental site is very suitable for the production of free-range chickens.

The experiment was performed from June to November of 2017, in the experimental site. A piece of sparse natural meadow with rich biodiversity was selected. The vegetation composition on the meadow was consistent and mainly consisted of small tree layer, shrub layer and herb layer from top to bottom. The small tree layer is dominated by ginkgo trees, with a height of 307 $\mathrm{cm}$ to $544 \mathrm{~cm}$. The shrub layer includes peach trees, plum trees, osmanthus trees, etc., with a height of $230 \mathrm{~cm}$ to 374 $\mathrm{cm}$. The herb layer includes Gramineae, Amaranthaceae, Moraceae, Solanaceae, Compositae, Cruciferae, Polygonaceae, Alismataceae, Rosaceae, etc., with a height of $2 \mathrm{~cm}$ to $58 \mathrm{~cm}$.

Table 1. Restrictionscheme of each age.

\begin{tabular}{|c|c|c|}
\hline Age (weeks) & $\begin{array}{c}\text { Daily feed (g/d } \\
\text { per broiler) }\end{array}$ & Feed collocation \\
\hline $0-5$ & ad libitum & $\begin{array}{c}100 \% \text { complete } \\
\text { formula feed }\end{array}$ \\
\hline $6-8$ & $60-65$ & $\begin{array}{c}100 \% \text { complete } \\
\text { formula feed }\end{array}$ \\
\hline $9-12$ & $68-80$ & $\begin{array}{c}80 \% \text { complete formula } \\
\text { feed and } 20 \% \text { corn }\end{array}$ \\
\hline $13-16$ & $85-100$ & $\begin{array}{c}70 \% \text { complete formula } \\
\text { feed and } 30 \% \text { corn }\end{array}$ \\
\hline $17-22$ & $105-120$ & $\begin{array}{c}60 \% \text { complete formula } \\
\text { feed and } 40 \% \text { corn }\end{array}$ \\
\hline
\end{tabular}

The experimental site possess the main representative characteristics of natural meadow of Sichuan Province. The meadow was divided into 3 parts, named group A, group B, and group C, where treatment groups (group A and B) have the same area of 0.2 hectare and was further divided into 3 sub-units for repeatable studies. In order to ensure the accuracy of this study, all the sub-units had consistent environmental conditions, size of the test area is related with the number of broilers.

\subsection{Statistical analysis}

The indicators of vegetation characteristics and soil physicochemical properties were analyzed by SAS (SAS Institute 2000), and the results were illustrated in the form of 'mean \pm standard deviation' in this paper. Means were compared and significance was declared based on least signifi cant difference at probability by $\mathrm{T}$ test, $\mathrm{P} \leq 0.05$.

\section{Results}

\section{1 broiler's excretion equivalent of nitrogen}

An average of $4.83 \mathrm{~kg}$ of dry broiler excretions were collected per chicken during the cage-rearing experiment, and the results showed that the protein content of excretion was $18.7 \%$, Through calculation, we found that the protein and nitrogen content of dry feces were $0.904 \mathrm{~kg}$ per broiler and $94.02 \mathrm{~g}$ per broiler, respectively.

A total of 360 broilers (Dahen 699 broiler) bred by Sichuan Animal Science Academy were reared indoor until the age of 5 weeks. From the age of 6 to 22 weeks, they were provided daily range access to groups A, B and C. Here, according to the vegetation characteristics and the carrying capacity of nitrogen $(112.74 \mathrm{~kg} / \mathrm{ha})$ on the test grassland, as well as the broiler's excretion equivalent of nitrogen, the carrying capacity of broilers on the test grassland was estimated to be 1200 broilers/ha per year; no matter how complex agroforestry systems are, the nitrogen carrying capacity of the land can be calculated according to the plant species. Considering the convention of two batches per year, the maximum stocking density was therefore calculated to be 600 broilers/ha. In order to further demonstrate the above calculation, 600 broilers/ha in group a (proper case, low-density group), and 1200 broilers/ha in group B (excessive case, high-density group) were designed to analyse the effects of different stocking densities on ecosystem. Each group was replicated three times in the sub-units. Group $\mathrm{C}$ was defined as a control group and kept idle for natural growth of plants. Broilers were fed in a restrictive scheme during the age of 6 to 22 weeks as given in Table 1. During the whole stocking period, the feeding points were moved from one corner to another every week in each sub-unit to keep the activities of chickens consistent and resulted in a uniform influence of feeding points on the meadow. The experiment was conducted in accordance with the Chinese guidelines for animal welfare and approved by the Animal Welfare Committee of Sichuan Animal Science Academy.

\subsection{Nitrogen carrying capacity of different stocking site}

The nitrogen carrying capacity of different stocking sites was determined according to the characteristics of vegetation based on the methods of literature review and investigation. According to the production practice of free range chicken, there are generally two batches per year.On the basis of determining the nitrogen absorption capacity of different sites, we can easily calculate the optimal density of characteristic stocking sites In the absence of 
artificial fertilizer application (Table 2).

Table 2. Nitrogen carrying capacity and outdoor stocking density of Free-range Broiler in different ccosystems.

\begin{tabular}{|c|c|c|}
\hline Stocking area & $\begin{array}{c}\text { Nitrogen carrying } \\
\text { capacity (kg per } \\
\text { year per ha) }\end{array}$ & $\begin{array}{c}\text { Stocking density } \\
\text { (birds per batches) }\end{array}$ \\
\hline $\begin{array}{c}\text { broad-leaved } \\
\text { forest land }\end{array}$ & 190.00 & 2010 \\
\hline $\begin{array}{c}\text { coniferous } \\
\text { forest land }\end{array}$ & 84.90 & 1900 \\
\hline $\begin{array}{c}\text { bamboo } \\
\text { forest land }\end{array}$ & 183.45 & 1320 \\
\hline $\begin{array}{c}\text { The orchard } \\
\text { grassland }\end{array}$ & 71.40 & 750 \\
\hline $\begin{array}{c}\text { barren hill or } \\
\text { bush }\end{array}$ & 113.55 & 600 \\
\hline
\end{tabular}

\subsection{Empirical research results}

\subsubsection{Changes of Vegetation Characteristics}

At the beginning of stocking, the total coverage, richness index, community diversity coefficient, fresh weight and dry weight of biomass above-ground of the meadow was $99.23 \%, 12.40,1.85,3,431.33 \mathrm{~g} / \mathrm{m} 2$ and $470.39 \mathrm{~g} / \mathrm{m}^{2}$, respectively. However at the end of stocking, the above indicators collected from the control group (group C) were $99.01 \%, 15.20,2.40,3,352.67 \mathrm{~g} / \mathrm{m}^{2}$ and $465.27 \mathrm{~g} / \mathrm{m}^{2}$, respectively. the total coverage, fresh weight and dry weight of biomass above-ground of the meadow in control group (group C, 0 broilers/hectare) have no significant difference between the pre- and post-stocking,, which suggested that climate changes made no significant effect on the above three indicators in this study. At the end of stocking, the total coverage, richness index, diversity coefficient, fresh weight and dry weight of biomass aboveground in low density stocking group (group A) was $25.06 \%, 65.79 \%, 57.92 \%, 32.71 \%$ and $32.66 \%$ lower than those in control group respectively. The changes of above indicators were more notable in high density group (group B), approximately $95.96 \%, 84.87 \%, 88.75 \%, 97.79 \%$ and $97.66 \%$ lower than those in control group respectively. Besides, the corresponding indicator value in low density stocking group was $18.75,2.50,3.74,30.49$ and 28.77 times of that in high density stocking group, respectively. The comparisons of vegetation characteristics between groups show that the demonstrated intuitively that freerange broiler production would significantly affect the natural growth of vegetation. Meanwhile, destruction of the vegetation became more serious as the stocking density increased, such as total coverage of group A reduced by 24.03 percentage points at the end of stocking,, that of group B reduced by 95.23 percentage points.

Dominate plant of pre- and post-stocking in each study group show that, at the beginning of stocking, the dominant plants of the meadow were Alternanthera philoxeroides, Humulus scandens, Amaranthus retroflexus and Polygonum hydropiper. While at the end of stocking, the dominant plants in control group (group C) were Alternanthera philoxeroides, Artemisia sphaerocephala, Rheum officinale and Capsella bursapastoris. In comparison, the dominant plants in low density group (group A) were Alternanthera philoxeroides, Coixlacryma and Dactylis glomerata. However, there was no dominant plant existed in high density group (group B), only the rhizomes of Wild arrowheads and Alternanthera philoxeroides remained underground. In control group, the plant grew naturally, thus the changes of dominant plants were caused by climate changes and growth law of plants. The comparison between treatment groups and control group at the end of stocking indicated that freerange broiler production changed both the species and quantity of dominant plants, and high density stocking would considerably affect the healthy growth of vegetation.

\subsubsection{Changes of Soil Physicochemical Properties}

The effects of free-range broiler production on soil were analyzed by comparing the changes of nutrients concentration, moisture, and $\mathrm{pH}$ value at the beginning and the end of stocking. The results in different layer were shown in table 5, 6 and 7. The soil physicochemical properties of the meadow showed limited change between the beginning and end of the stocking in control group (group C). However the above indicators in treatment groups (group A and B) measured at the end of stocking were significantly changed, it showed that $0-10 \mathrm{~cm}$ layer is the most influential layer. Therefore the results of $0-10$ $\mathrm{cm}$ layer will be the focus of present study. Compared with control group, the content of moisture, total nitrogen, organic matter, available phosphorus, available nitrogen and available potassium in low density group (group A) were $0.29 \%, 0.03 \%, 0.39 \%, 5.11 \%, 67.25 \%$ and $128.91 \%$ higher respectively, and those in high density group (group B) were $1.14 \%, 0.13 \%, 1.13 \%, 25.21 \%, 191.70 \%$ and $234.42 \%$ higher respectively. Meanwhile the $\mathrm{pH}$ value in low and high density group was $4.38 \%$ and $9.73 \%$ lower than that in control group, respectively. Moreover, the amplitude of change in high density group was 3.93, 4.33, $2.89,4.93,2.85,1.82$ and 2.22 times of that in low density group respectively. The results illustrated that free-range broiler production modified soil physicochemical properties, leading to an increase of soil nutrients and moisture, as well as a decrease of $\mathrm{pH}$ value, which finally changed the soil from alkaline into weak acid.

\section{Discussion and conclusions}

Density control is very important for free-range broiler production. Excessive stocking density will destroy the ecosystem, cause soil hardening and acidification, and affect the healthy growth of birds, which is not conducive to industrial development.

It was crucial to select the stocking area according to the local vegetation characteristics for free-range broiler production, of course, It's also a good way to cultivate 
plants and pastures with competitive advantage in the stock area. On the other hand, some leguminous plants could be planted artificially for bird's feeding to reach the goal of saving feed.

Through the combination of theoretical derivation and investigation and research, this paper proposed the feeding density of free-range broiler in different stocking ecosystems based on the nitrogen cycle, and proved the correctness of the research idea and density parameters through empirical research, which provided the key technical parameters for scientific guidance of free range chicken production.

\section{Acknowledgments}

We are grateful to all of the people for their help with sample collection. This work was supported by Chinese National Agriculture Research System (CARS-41-G04), Key Technology Support Program of Sichuan Province (2019YFN0009, 2021YFYZ0031).

\section{Reference}

1. G. D. Almeida, L.K. Hinrichsen, K. Horsted, S. Thamsborg, J. E. Hermansen, Feed intake and activity level of two broiler genotypes foraging different types of vegetation in the finishing period. Poult. Sci. 91(2012)

2. M. Singh, I. Ruhnke, C.D. Koning, K. Drake, A.G. Skerman, G.N. Hinch, P.C. Glatz, Demographics and practices of semi-intensive free-range farming systems in Australia with an outdoor stocking density of and practices of sem. PloS One,12(2017)

3. P.R. Warman, J.M.Cooper, Fertilization of a mixed forage crop with fresh and composted chicken manure and NPK fertilizer: effects on dry matter yield and soil and tissue N, P and K. Canadian Journal of Soil Science, 80(2000)

4. S. Kratz, J. Rogasik, and E. Schnug, Changes in soil nitrogen and phosphorus under different broiler production systems. J. Environ. Qual. 33(2004)

5. L.M. Stadig, F.A.M. Tuyttens, T.B. Rodenburg, B. Vandecasteele, B. Ampe, B. Reubens, Interactions between broiler chickens, soil parameters and short rotation coppice willow in a free-range system. Agroecology and Sustainable Food Systems, 43(2019). 